\title{
A Novel of Internal Corrosion Assessment Methods on Drinking Water Distribution Pipelines
}

\author{
Edi Septe ${ }^{1,2, *}$, Nizwardi Jalinus ${ }^{2}$, and Refdinal ${ }^{2}$ \\ ${ }^{1}$ Mechanical Engineering Dept., Industrial Engineering Faculty, Universitas Bung Hatta, Indonesia \\ ${ }^{2}$ Doctoral Program Vocational Education and Technology Department, Engineering Faculty, \\ Universitas Negeri Padang, Indonesia
}

\begin{abstract}
Various methods of corrosion assessment on drinking water distribution pipelines have been reviewed in this paper. Five methods of corrosion assessment consisting of sampling method, scanning method, ultrasonic testing method, electromagnetic inspection method and corrosion index assessments described provide valuable information regarding their implementation mechanisms. Since each method has its advantages and limitations, the application of methods on the pipeline must consider the environmental conditions of the pipeline to be inspected, as well as the equipment and resources available.
\end{abstract}

\section{Introduction}

The main pipeline consist of iron pipes such as gray cast-iron pipes, ductile cast iron pipes and steel pipes [1] is susceptible to internal corrosion [2] which causes the dissolution of iron into the water, and forms an iron oxide that produces particulate iron compounds in water and causes "red water" that affects the water quality [3]. Corrosion that occurs in pipes can vary significantly in one segment with another segment [4] and it is the key factor affecting failure pressure of the pipeline [5].

Drinking water distribution pipelines are generally planned for a period of more than 40 years to ensure water supplies to more than $90 \%$ of the city's population smoothly with good quality [6] [7]. To ensure the quality of the water supply, as well as to maintain the stability of drinking water supply in a sustainable manner, the drinking water company should rehabilitate the damaged pipes or old pipes systematically [3]. Rehabilitation of pipelines requires up to date data and information on pipeline conditions. Without proper information, it can lead to un optimal rehabilitation associated with cost, time and method [4]. The assessment of pipe corrosion is one way to obtain information: the condition of the pipeline which is necessary to avoid failure of equipment that may cause interruption of operation, about the relationship between the corrosion process and the operating variables, with the result that pipes can be used more efficiently [8].

\footnotetext{
* Corresponding author: edysepte@yahoo.com
} 
The assessment of corrosion of drinking water distribution pipelines can be focused on three factors: physical, operational and environmental factors. Physical factor parameters are pipe mass loss within a certain time period, which can be converted into pipeline corrosion rate per year. The operational factor parameters are related to the performance of water flow in the pipeline, in the form of transient pressure, flow rate and flow capacity. Environmental factors that affect the occurrence of damage to the pipeline consists of external and internal environment. External environmental parameters are soil corrosivity or resistivity, soil moisture, $\mathrm{pH}$, sulphide and chloride concentration, whereas internal environmental parameters are water aggressiveness affecting pipe corrosion, such as $\mathrm{pH}$, hardness and oxygen dissolution [9].

Based on the corrosion assessment factor, corrosion assessment can be done directly and indirectly. There are several methods of corrosion assessment on applicable drinking water distribution pipelines. The intention of this article is to describe several methods of internal corrosion assessment of drinking water distribution pipelines as part of pipeline assessment technology.

\section{Literature Review}

To improve the reliability of the water supply system, it is necessary to conduct a pipeline inspection, because if the extent of damage to the pipe wall and its operating period is known, it can calculate the average corrosion rate as the basis for decision making on pipe replacement or rehabilitation [7].

The study to determine the condition and predict the life time of the pipe future of the ductile cast-iron pipes that are used as drinking water distribution pipes was conducted [3]. Assessment is done with the impact of elastic-wave method on the piece of pipe after receiving the mechanical loading at one end. Because pipeline stiffness will decrease due to decrease of pipe thickness caused by corrosion, the thickness of the pipe is known based on the peak vibration frequency data of the pipe [10]. While the hole on the surface of the pipe is known based on the frequency distribution of pipe vibration waves, because the frequency of pipe waves that have a hole in the distribution of a lower range than the massive pipe frequency waves [3].

Pipeline corrosion assessment can also be done through coupon testing [11]. Investigated the corrosion rate of reclaimed water distribution pipes through coupon testing is performed by making a closed test installation with a test chamber as a coupon rack, located in the middle of the installation. The weight changes that occur in each coupon over a period of time become the basis for calculating coupon corrosion rate, as an indicator of corrosion assessment [12].

Corrosion assessment on drinking water distribution pipelines can also conducted based on acoustic resonance technology method [4]. The assessment of corrosion is done using pipe scanner which has a number of ultrasound transducers, as well as data acquisition and data storage. Pipe scanners are inserted into the pipe through a hole made at the beginning of the pipe and moved along the inspected pipe. Acoustic resonance technology refers to the use of wide-band acoustic pulses to generate resonance modes in the pipe. This mode will be reflected from the pipe wall and received by the transducer for further analysis [13]. The area that goes in the resonance and from which the acoustic signal is reflected is called 'foot print'. The acoustic reflection signal contains information such as wall thickness and corrosion in 'foot print'. The analysis can determine the thickness of the pipe wall, although the pipe is covered by corrosion or sediment products. This method can determine the thickness of the remaining pipe wall in the range of 1.5 to $25 \mathrm{~mm}$, distinguish between corrosion inside and outside the pipe, and indicate the position and area of rust, tuberculosis and sedimentation in the pipe [4][14]. 
Non-destructive techniques can be done to inspect water pipes made of steel and ductile cast iron are based on eddy current and ultrasonic technique [15] [16]. Ultrasonic testing method used the ultrasonic waves with high frequency above $20 \mathrm{Khz}$. The ultrasonic testing system consists of several functional units such as receiver waves, transducers, and display devices. Receiver waves are electronic devices that can generate high-voltage electrical energy that makes high-frequency transducers produce ultrasonic energy. Ultrasonic waves are generated by changes in electrical energy to the mechanical energy of a transducer or probe, through a piezoelectric effect. The piezoelectric effect is a reversible effect, which in the event of a change of electrical energy to a mechanical, then a change of mechanical energy to electrical energy also occurs.

Sound energy will spread in the form of waves through pipe material and when there are defects detected by waves, some energy will be reflected back from the defective surface. Ultrasonic scan, has the ability to detect metal thickness changes down to less than $0.2 \mathrm{~mm}$ [17]. Examination of thickness and presence of defects in the pipes with ultrasonic waves can be done through resonance techniques, transmission techniques, and echo techniques. A resonance technique that measures the thickness of the material through measurement of ultrasonic wave lengths that can lead to maximum resonance in the material and the determination of defects based on resonance changes. The transmission technique determines the defect based on the decrease in the intensity of the ultrasonic wave received by the receiver probe. The echo technique determines the thickness of the material, the location and the size of the defect based on the time of propagation and wave amplitude received by the probe [15].

Electromagnetic inspection method is done by application of remote field eddy current. This method is based on the measurement of the attenuation and phase delay of the electromagnetic signal as it passes through the thickness of the metal pipe wall. Pipe inspection is performed using an exciter coil that produces a direct (internal) electromagnetic field moving inside the pipe, but its power will weaken rapidly because of the circumferential eddy current induced in the wall of the conductor pipe. Simultaneously, the exciter produces another indirect (external) field that travels through the wall of the pipe with a small attenuation. The change of field strength and attenuation depends on the thickness of the wall of the pipe thus from this change allows the determination of the thickness of the pipe wall [15][18].

Corrosion assessment on drinking water distribution pipelines can also be performed based on the water condition in the pipelines. The water condition described as the corrosion index which can cause corrosion impact to the pipe walls. Langelier Saturation Index (LSI), Ryznar Stability Index (RSI), Larson-Skold (LS), Puckorius Index Scaling (PSI) and Aggressive Index (AI), are usually used to determine whether water flowing in a pipe affects corrosion or forms a water sediment on a pipe wall [19][20].

Physicochemical reactions that occur between metals and environments that have electrochemical properties will cause changes in the properties of metals. Corrosive water in the pipe will dissolve the pipe material during flow and this causes many problems [21].

\section{Recommendation for Future Work}

There are five methods that can be used to assess the corrosion of drinking water distribution pipes. In practice, the methods have their own advantages and disadvantages. The sampling method provides pipeline condition information at a particular location at which the sample was taken [11]. This method can't provide comprehensive information from the inspected pipeline. While the scanning method can provide more comprehensive information on the inner pipe surface conditions [4][14]. Ultrasonic testing and electromagnetic inspection may provide better pipeline condition information, but this method requires a skills operator and 
need a relatively larger cost. The corrosion index assessment method through the flowing water examination is a relatively easy method, but the information obtained from the application of this method does not directly describe the condition of the pipe surface.

Based on the parameters of corrosion assessment, the application of the sampling method with impact-elastic-wave method, scanning method, ultrasonic testing and electromagnetic inspection are performed for assessment the physical factors. Meanwhile the sampling method with coupon testing is done for operational parameters assessment, because in this test can be varied velocity, pressure and water temperature flowing in the pipe. Moreover, corrosion assessment by corrosion index method is an assessment based on the parameters of the pipe internal environment. To get better information on corrosion assessment of pipelines, two methods can be implemented on the pipelines to be inspected.

\section{Conclusion}

Several methods may be undertaken for assessment of corrosion of drinking water distribution pipelines, which provide information on pipeline conditions and environmental or water conditions that flow within the pipeline. Five methods of pipe corrosion assessment have been proposed in this article and each method has advantages and limitations. To conduct an effective corrosion assessment, the selection of methods to be applied to a pipeline must consider the environmental conditions of the pipeline to be inspected, as well as the equipment and resources available. The data and information obtained from the corrosion assessment can be considered for the decision of rehabilitation or replacement of drinking water distribution pipelines.

\section{References}

1. Y. Hou, D. Lei, S. Li, W. Yang, and C.Q Li, Experimental Investigation on Corrosion Effect on Mechanical Properties of Buried Metal Pipes, International Journal of Corrosion, Volume 2016, Article ID 5808372, 13 pages (2016)

2. A.C. Benjamin, J.L.F. Freire, R.D. Vieira, D.J.S. Cunha, Interaction of Corrosion Defects in Pipelines - Part 1: Fundamentals, International Journal of Pressure Vessels and Piping (2016)

3. Y. Kobayashi, Y. Takahashi, T. Kamada, A. Koizumi and M. Fujiwara, 2010, Corrosion Assessment of Aging Drinking Water Pipes by Impact Elastic-Wave Method, Water Practice and Technology, 5, 3 (2010)

4. E. Kloosterman, Condition Assessment of Metallic Water Mains by Internal Pipe Inspection, ( $4^{\text {th }}$ Pipeline Technology Conference, Hannover Germany, April 22-23, 2009)

5. Y. Chen, H. Zhang, J. Zhang, X. Liu, X. Li, J. Zhou, Failure Assessment of X80 Pipeline With Interacting Corrosion Defects, (Engineering Failure Analysis, 2014)

6. R. Gražulevičienè and G. Balčius, Assessment of Iron and Manganese Concentration Changes in Kaunas City Drinking Water Distribution System, Environmental Research, Engineering and Management, 4, 50, 37-43 (2009)

7. V. Maslak, N. Nasonkina, V. Sakhnovskaya, M. Gutarova, S. Antonenko and D. Nemova, Evaluation of Technical Condition of Water Supply Networks on Undermined Territories, Procedia Engineering 117, 980-989 ( 2015 )

8. S.A. Protain, An Introduction to Corrosion Monitoring. Protection Anticorrosiva, (Master Document 0147 Issue E June 2005). 
9. E.Septe, A. Naumar and A.H. Mohammed, A Review of Corrosion Assessment Model and Parameters of Drinking Water Distribution Pipelines, Jurnal Teknologi UTM Malaysia, 69, 2 (2014).

10. S. Uchida, T. Kamada, T. Iwasaki, S. Iwano and H.S. Lee, A Study on Frequency Analysis Methods for Concrete Thickness Estimation by Impact Elastic-Wave Method, (Proceeding of Third International Conference on Sustainable Construction Materials and Technologies, Kyoto, Japan, August 18-21, 2013)

11. H. Lee, U. Rasheed and M. Kong, A Study on The Comparison of Corrosion in Water Supply Pipes Due to Tap Water (TW) and Reclaimed Water (RW), Water, 10, 4 (2018)

12. C.E. Chuka, Odio. B.O, Chukwuneke J.L, Sinebe. J.E. Investigation of The Effect of Corrosion on Mild Steel in Five Different Environments, International Journal Of Scientific \& Technology Research, 3, 7 (2014).

13. R. Urayama, T. Takagi, T. Uchimoto, S. Kanemoto, T. Ohira and T. Kikuchi, Implementation of Electromagnetic Acoustic Resonance in Pipe Inspection, E-Journal of Advanced Maintenance, 5, 1 (2013).

14. L. Djeddi, R. Khelif, S. Benmedakhene and J. Favergeon, Reliability of Acoustic Emission as a Technique to Detect Corrosion and Stress Corrosion Cracking on Prestressing Steel Strands, International Journal of Electrochemical Science, 8, 8356 8370 (2013).

15. B. Rajani and Y. Kleiner, Non-Destructive Inspection Techniques to Determine Structural Distress Indicators in Water Mains, )Proceedings of Evaluation and Control of Water Loss in Urban Water Networks, Valencia, Spain, June 21-25, 2004)

16. N. Ulapane, A. Alempijevic, T.V. Calleja and J.V. Miro, Pulsed Eddy Current Sensing for Critical Pipe Condition Assessment, Sensors, 17, 2208 (2017)

17. B.F. Al-Daajani, N.M. Al-Anazi, A.M. El-Sherik and A.I. AbdulHadi, Assessment of Advanced Corrosion Monitoring Technology for Pipeline Integrity, Saudi Aramco Journal of Technology, 2016, 41-46 (2016)

18. X. Xu, M. Liu, Z. Zhang and Y. Jia, A Novel High Sensitivity Sensor for Remote Field Eddy Current Non-Destructive Testing Based on Orthogonal Magnetic Field,, Sensors, 14, 24098-24115 (2014)

19. A. Dargahi, R. Shokri, M. Mohammadi, A. Azizi, L. Tabandeh, A. Jamshidi and S. Beidaghi, Investigating of The Corrosion and Deposition Potentials of Drinking Water Sources Using Corrosion Index: A Case Study of Dehloran, Journal of Chemical and Pharmaceutical Sciences, Special Issue 7, 73-79 (2016)

20. A. Amouei, S.H. Fallah, H. Asgharnia, A.R. Yari and M. Mahmoudi, Corrosion and Scaling Potential in Drinking Water Distribution of Babol, Northern Iran Based on the Scaling and Corrosion Indices, Archives of Hygiene Sciences, 6, 1 (2017).

21. S. Shahmohammadi, A. Noori, S. Karami, A. Amini, B. Shahmoradi, S.S. Ardakani. S.M. Lee and R.R. Pawar, A Study on Corrosion and Scaling Potential of Drinking Water Supply Resources in Rural Areas of Sarvabad, West of Iran, Journal of Advances in Environmental Health Research, 6, 53-61 (2018). 